\title{
Free Convection Heat Transfer Around a Cylinder Embedded in an Enclosure Filled with Porous Media
}

\section{Authors affiliations:}

1) Mech. Eng. Dept., University of Technology, Baghdad-Iraq Sah Jumaily66@yahoo.com

$\left.2^{*}\right)$ Mech. Eng. Dept., University of Technology, Baghdad-Iraq abeeraamer537@gmail.com

\section{Paper History:}

Received: $25^{\text {th }}$ Oct. 2019

Revised: $28^{\text {st }}$ Dec. 2019

Accepted: 29th Jan. 2020

\author{
Suhad A. Rasheed ${ }^{1}$, Abeer A. Mahmood ${ }^{2 *}$
}

\begin{abstract}
An experimental and theoretical study of free convection heat transfer for a cylinder placed in an iron test section of dimensions $(0.2 \times 0.2 \times 0.2$ $\mathrm{m} 3)$, the test section filled with saturated porous material glass balls (5 $\mathrm{mm}$ ), and the air is the working fluid with Raleigh number $(7692.6 \leq \mathrm{Ra}$ $\leq 17654)$. The circular cylinder heater $(\mathrm{D}=0.015 \mathrm{~m}, \mathrm{~L}=0.2 \mathrm{~m})$ is heated electrically, made of Copper and located in different positions (in X \& Y direction). The theoretical part includes solving the free convection heat transfer using the ANSYS program (fluent). The experimental and theoretical results showed that the surface temperature values around the cylinder perimeter when changing its position within the test section are changing as moving up and down where the effect of buoyancy force appears. The maximum difference between the upper and lower position at the experimental result is $7.22 \%$, and the average Nusselt number increases with Raleigh number and heat flux. Also, the experimental results showed that the use of porous material significantly improves the heat transfer by $48.6 \%$. The maximum percentage change between the experimental and theoretical results is $5.46 \%$. Moreover, experimental correlations were achieved, and a comparison was performed between the present results with the previous studies and it gives a good agreement.
\end{abstract}

Keywords: Free Convection, Porous Media, Heater Model

\section{انتقال الحرارة بالملل الحر حول اسطوانة مدججة في حاوية مليئة بالوسائط المسامية}

$$
\begin{aligned}
& \text { عبير عامر محود ، سهاد عبد المميد رشيد } \\
& \text { دراسة عملية ونظرية لأنتقال الحرارة بالممل الحر لأسطوانة مغمورة في وسط مساي مشبع (كرات زجاجية }
\end{aligned}
$$

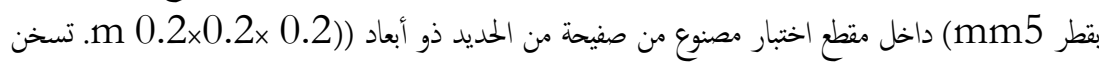

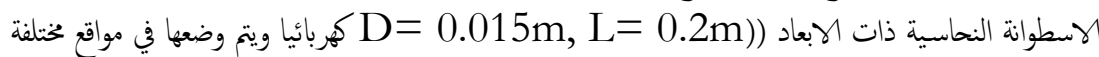

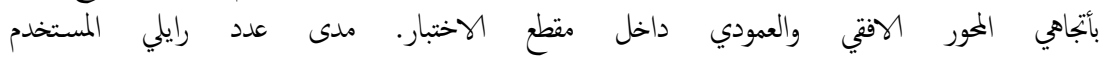

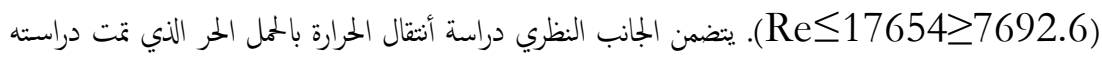

$$
\begin{aligned}
& \text { في الجانب التجريبي باستخدام برنامج (ANSYS (Fluent) وإجراء مقارنة بينها. أظهرت النتابُج العملية }
\end{aligned}
$$

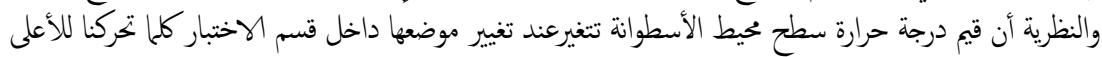

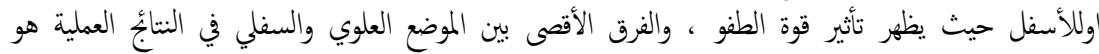

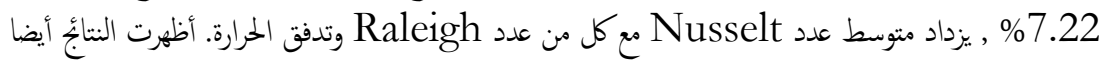

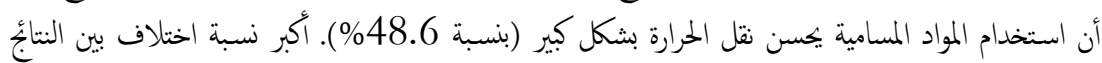

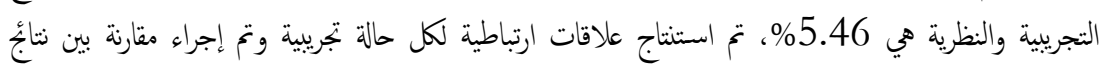

$$
\begin{aligned}
& \text { البحث الحالي والدراسات السابقة ، وقد اعطى الثفاقًا جيدًا. } \\
& \text { الكلمات المفتاحية: الممل القسري ، المادة المسامية ، عنصر التسخين الماند }
\end{aligned}
$$

\section{Nomenclature:}

symbol

A
Cross sectional area of the test section

Surface area of the heater model $\mathrm{c}_{\mathrm{p}}$

$D$

Gr

b
Specific heat of air Diameter of the circle cylinder

J/kg.K

Units

$m^{2}$

$m^{2}$

Grashof number

The average heat transfer coefficient m

$\mathrm{W} / \mathrm{m}^{2} \cdot{ }^{\circ} \mathrm{C}$ 


\begin{tabular}{|c|c|c|}
\hline$b_{\theta}$ & $\begin{array}{c}\text { The local heat transfer } \\
\text { coefficient }\end{array}$ & $W / m^{2} \cdot{ }^{\circ} \mathrm{C}$ \\
\hline$I$ & Electrical Current & $A$ \\
\hline$\varepsilon$ & Porosity & \\
\hline$k_{f}$ & Thermal conductivity of air & $W / m \cdot K$ \\
\hline$k_{m}$ & $\begin{array}{c}\text { Effective thermal } \\
\text { conductivity of porous } \\
\text { media }\end{array}$ & $W / m \cdot K$ \\
\hline$k_{s}$ & $\begin{array}{l}\text { Thermal conductivity of } \\
\text { spheres (beads) }\end{array}$ & $W / m \cdot K$ \\
\hline$m_{\text {aur }}$ & Mass flow rate of air & $\mathrm{kg} / \mathrm{s}$ \\
\hline$N u \theta$ & Local Nusselt number & - \\
\hline$N u$ & Average Nusselt number & - \\
\hline $\operatorname{Pr}$ & Prandtl number & - \\
\hline $\operatorname{Pr}_{b}$ & Bulk prandtl number & - \\
\hline $\operatorname{Pr}_{w}$ & Wall prandtl number & - \\
\hline$q$ & Heat flux & $W / m^{2}$ \\
\hline $\mathrm{R} a$ & Raleigh number & - \\
\hline$T_{\text {in }}$ & $\begin{array}{c}\text { Temperature inlet airflow } \\
\text { of test section }\end{array}$ & ${ }^{\circ} \mathrm{C}$ \\
\hline$T_{\text {out }}$ & $\begin{array}{c}\text { Temperature outlet airflow } \\
\text { of test section }\end{array}$ & ${ }^{\circ} \mathrm{C}$ \\
\hline$T_{w}$ & $\begin{array}{c}\text { Surface temperature of the } \\
\text { heater model }\end{array}$ & ${ }^{\circ} \mathrm{C}$ \\
\hline$T_{w} \theta$ & $\begin{array}{c}\text { The local surface } \\
\text { temperature of heater } \\
\text { model }\end{array}$ & ${ }^{\circ} \mathrm{C}$ \\
\hline$U$ & $\begin{array}{l}\text { Average Velocity in the } \\
\text { test section }\end{array}$ & $m / s$ \\
\hline$V$ & Electrical voltage & $V$ \\
\hline$\propto$ & permeability & $\mathrm{m}^{2}$ \\
\hline$\theta$ & $\begin{array}{l}\text { The angles around the } \\
\text { perimeter of heater }\end{array}$ & degree \\
\hline
\end{tabular}

\section{Introduction}

Natural convection is a very important topic due to its many applications in many fields of nature, and although there is no forced speed that generates this type of convection, however, the natural convection currents are generated inside the fluid which urge it to flow due to the buoyancy effects. As seen in many devices that include multiple methods of heat transfer, which influence the heat transfer rates or the operating cost, the natural convection plays an important role in the design or performance of the device, which is much preferred over forced convection. The natural convection also occurs in the saturated porous medium of the fluid (a solid that contains holes and gaps that connect with each other as passages and pores through which the fluid will flow $\left.{ }^{[1]}\right)$. The porous medium is used in many fields and applications, as it has entered its use in the field of industry, geology and nuclear industries, as well as it has an important role in the field of heat transfer and in the field of energy conservation, such as the granular or porous insulators and high-power electrical coils structures [2]. The porous medium is also used in nuclear reactors, as it pulls the sudden heat generated from the dissolution of the nuclear fuel particles due to sudden accidents that affect the nuclear reactors. It is also used in drying and storage of absorbed solar energy and also used in building materials and as insulating materials [3]. This study investigates experimentally and theoretically the characteristics of free convection heat transfer for a circular heater cylinder at different locations in the test section, with and without porous media at a constant heat flux.

Nawaf H. Saeid [4] 2006, utilized a thermally non-equilibrium model to study the natural convection of a cylinder immersed horizontally in a porous medium. The governing equations were converted to dimensionless form by entering the boundary layer dimensionless variables. The developed code results were verified with different mesh sizes that can be utilized for the thermal equilibrium condition as benchmark results. Numerical results are obtained to analyze the effect of the porosity scaled thermal conductivity ratio $K_{r}$, and the heat transfer coefficient between the fluid and solid phases $H$. The total average Nusselt number increased with the increasing of $\mathrm{k}_{\mathrm{r}}$ or $\mathrm{H}$.

M. Ashjaee et Al. [5] 2007, conducted an experimental research to study a laminar free convection heat transfer from horizontal isothermal cylinders arranged in a vertical and inclined array in the air. The cylinder spacing for the vertical and inclined array was varied from 2 to 5 cylinder diameters (center to center). In the inclined array, the horizontal spacing was varied from 0 to 2 cylinder diameter. The effect of Rayleigh number and cylinder spacing (the vertical and horizontal) on the heat transfer for each singular cylinder and for all arrays was investigated. Correlations of heat transfer were developed. And, the results showed that the heat transfer from a singular cylinder in the array depends on its location relative to the others. The Rayleigh number used was varied between $10^{3}$ and, $3 \times 10^{3}$.

Yorwearth L. Jamin [6] 2008, performed an experimental research, the main objective of it is to quantify and compare the improvement of heat transfer of carbon foam used as a porous media and aluminum fins in free convection. The research measured the steady-state heat transfer of a heated tube located vertically, in case of presence and absence of the porous media. The greatest increase in Nusselt number was produced by a solid carbon foam cover, which was about 2.5 times larger than a bare copper tube.

Ş. Özgür Atayılmaz et al. [7] 2009, achieved an experimental and numerical research of free convection heat transfer from a horizontal cylinder at constant heat flux. Two cylinders were used of 4.8 and $9.45 \mathrm{~mm}$ diameter. The experimental examination was taken place in different environmental temperatures in an air-conditioned room. The environmental and cylinder surface temperatures ranged between $10^{\circ} \mathrm{C}-40{ }^{\circ} \mathrm{C}$ and $20{ }^{\circ} \mathrm{C}$ - $60{ }^{\circ} \mathrm{C}$, respectively. Correlation for the average Nusselt number across the cylinder was obtained in the range of $7.4 \times 10 \leq \mathrm{Ra} \leq 3.4 \times 10^{3}$. The problem was also investigated numerically and then compared with the experimental results. 
Ahmed Hassen Ahmed (8) 2009, carried out a theoretical and practical study of free convection from a submerged cylinder in a saturated porous medium. The theoretical side included the derivation of the governing equations of momentum and energy by utilizing the Darcy model. The peclet number was installed within the natural transition range with changing Raleigh number values ranging from 10 to 50 respectively. The practical side included the construction of an experimental model consisting of a steel cylinder with a diameter of $20 \mathrm{~mm}$ heated electrically and immersed in glass balls $(12 \mathrm{~mm})$ placed in the middle of the test. Both theoretical and practical results showed that the steady-state heat transfer rate increased with increasing Raleigh

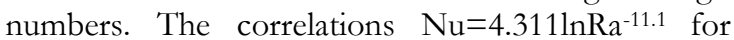
experimental and $\mathrm{Nu}=2.155 \ln \mathrm{Ra}^{-3.98}$ for theoretical.

P. Nagaraju [9] 2011, carried out an experimental study for a rectangular cavity filled with a porous media (iron or glass balls) of a different porosity. The bottom plate of the box was kept at a uniform temperature $\left(T_{h}\right)$, and it was higher than the temperature $T_{c}$ of the top plate. The tests were performed for both opened and closed systems in horizontal as well as the vertical orientation. The results indicated that using the porous media can transport further energy than a fluid alone if the porous medium is greatly permeable and the thermal conductivity of the solid materials is higher than that of the fluid. It was seen that the time was taken to arrive the thermal steady-state in the horizontal direction was less as compared to the vertical direction. It was observed that the values of temperature for iron balls were about $10 \%$ more when compared with the glass balls and about $18 \%$ higher for the vertical direction as compared to the horizontal direction.

E. Shakeri et al. [10] 2012, analyzed the natural convection heat transfer over a cylinder placed vertically in a porous medium with variable surface temperature distributions. A two-temperature model of heat transfer was employed. Both equations of coupled momentum and energy were displayed and then converted to ordinary differential equations. The streamlines, velocity, temperature distributions and local Nusselt numbers of both solid and fluid phases were shown.

Stig Grafsrønningen et al. [11] 2013, carried out an experimental research of a free convection heat transfer from three horizontally stainless steel heated cylinders of inner diameter $51 \mathrm{~mm}$ and the outer diameter of $54 \mathrm{~mm}$, arranged in a vertical array, with different cylinder spacings (2D, 3D, 4D, and 5D). Nusselt numbers for Rayleigh numbers 1.96E7 and $5.35 \mathrm{E} 7$ were presented with separation distance 2D, 3D, 4D, and 5D. The heat transfer enhancement on the upper cylinders was due to the turbulent mixing. The Nusselt number of the top cylinder in the threecylinder array increased relative to the lowermost cylinder but was similar to the second cylinder. The Nusselt number of the second cylinder increased relative to the lower cylinder for all separation distances.
Anna A. Bocharova [12] 2016, described the free convection flow on a vertical impermeable surface surrounded by a semi-infinite porous medium with the given heat transfer from the vertical surface. On the basis of asymptotic analysis of energy and momentum equations, the viscous boundary layer thickness was determined as the quantity of the order $R a^{-1}$. An analytical solution was obtained for the temperature and longitudinal velocity; this analytical solution achieved the no-slip condition and was applicable uniformly throughout the boundary layer region.

Sandra Corasaniti [13] 2017, conducted an experimental investigation of free convection around a vertical cylinder (thermal probe) of $1.5 \mathrm{~mm}$ diameter and $150 \mathrm{~mm}$ length immersed in a glass beads porous medium of $3 \mathrm{~mm}$ diameter saturated with water. The thermal probe contains a thermocouple and spiraled around it a platinum wire heater. Three temperature sensors at different heights on the surface of the vertical cylinder were used to investigate the natural convection around the thermal probe. Local and average Nusselt numbers on the height of the vertical cylinder were determined.

Hosny Abou-Ziyan et al. [14] 2017, investigated the result of free convection from a short horizontal cylinder with aspect ratio $(\mathrm{L} / \mathrm{D}=8)$ to five fluids of large Prandtl number, 2 fluids of weakly power-law fluids and 3-Newtonian fluids, under fixed heat flux. At various bulk temperatures $\left(40-175^{\circ} \mathrm{C}\right)$ and heat fluxes $\left(0.66-104 \mathrm{~kW} / \mathrm{m}^{2}\right)$ that correspond to heat generation about 0.7 to $113 \mathrm{MW} / \mathrm{m}^{3}$, the results showed that Newtonian fluids achieved higher free convection heat transfer coefficient than the powerlaw fluids by $16 \%$ or more. Correlations cover Rayleigh number $\left(\mathrm{Ra}^{*}=\mathrm{g} \beta \mathrm{q} d^{4} / \mathrm{kv} \alpha\right)$ from $6.1 \times 10^{4}$ to $6.88 \times 10^{8}$, Grashof number $\left(\mathrm{Gr}^{*}=\mathrm{g} \beta \mathrm{q} d^{4} / \mathrm{k} v^{2}\right)$ from 33 to $1.68 \times 10^{7}$, Prandtl numbers $(\operatorname{Pr}=\mathrm{cp} \mu / \mathrm{k})$ from 30 to 1850 , Prandtl numbers ratio (Prb/Prw) from 1.03 to 133 and heat generation parameter from 0.001 to 0.009 .

\section{Scope of the Present Work}

The literature survey presented a number of studies in the field of free convection heat transfer around single or number of cylinders with and without porous media. This study investigates experimentally and theoretically, the characteristics of free convection heat transfer for circular heater cylinder at different locations in the test section, with $\&$ without porous media at constant heat flux.

\section{Theoretical solution}

In this section, the thermal performance and electrical characteristics of cylinder cooling by porous media (free convection) are evaluated. This section describes the physical model by using the SOLID WORK (2018) program and includes the assumptions, the boundary conditions, and mesh generation to investigate the thermal performance of the cylinder embedded in porous media. There are many parameters (air inlet temperature, air outlet 
temperature, the surface temperature of the heater) that have been employed for solving the equations of continuity, momentum, and energy using the software (Ansys Fluent 18). Porous media are created by inserting a momentum source term ${ }^{[15]}$ to the standard fluid flow equations. The source term (S) is formed of two parts; the first term in the right side of equation (1) is a viscous loss term (Darcy term), while the second term in the right side of equation (1) is an inertial loss:

$\mathrm{S}=-\left(\frac{\mu}{\alpha} v i+\mathrm{C}_{2} \frac{1}{2} \rho|v| v i\right)$ where $\alpha$ is permeability

\subsection{Physical model:}

The geometry system used for the solution is two dimensions space $(0.2 \times 0.2 \mathrm{~m})$ which in turn represented the boundary of the test section that used in the experimental part. This space contains a circle of $(0.015 \mathrm{~m})$ diameter which is placed in different locations in each test. It is drawn by applying a software program called solid work 2018 , as shown in fig. (1).

\subsection{Assumptions:}

The working fluid is air, and the flow characteristics are assumed to be as follows: Steady state, Gravitational acceleration in Y-axis, Ideal gas, Two dimensions, and Laminar.

\subsection{Mesh - generation:}

In this research, the mesh was generated by using Ansys workbench. A correct computational mesh creation was of eminent significance to simulate the ANSYS (fluent). The results precision was meshing dependent, therefore, it is necessary to reduce the domain mesh size step by step to a suitable level where any increase in the nodes number does not lead to great changes in the results. The mesh for the test section and cylinder is shown in fig. (1). For the present case, an average of (15943) nodes are used, after several attempts.

\subsection{Boundary conditions:}

- Inlet boundary condition: The inlet pressure is assumed to be atmospheric pressure, and the inlet temperature is $31^{\circ} \mathrm{C}$

- Outlet boundary condition: The outlet pressure is assumed to be atmospheric pressure

- The heat flux from the heater is $40764-94268$ $\left(\mathrm{W} / \mathrm{m}^{2}\right)$

- Cell zone condition: In case of presence of porous media, a porous zone was chosen, the porosity (0.463) was selected, and the type of porous media used in the experimental work was (glass beads)

\subsection{Governing equations:}

The conservation continuity, momentum, and energy equations are written as follows[16]:

* Conservation of mass equation:

$$
\frac{\partial u}{\partial x}+\frac{\partial v}{\partial y}=0
$$

Where $\mathrm{u}$ and $\mathrm{v}$ are velocity components corresponding to the $\mathrm{x}$ and $\mathrm{y}$ directions, respectively.

Conservation of momentum equation:

$$
\begin{gathered}
\frac{1}{\varepsilon^{2}}\left[\mathrm{u} \frac{\partial \mathrm{u}}{\partial \mathrm{x}}+v \frac{\partial v}{\partial \mathrm{y}}\right]=-\frac{1}{\rho f} \frac{\partial \mathrm{p}}{\partial \mathrm{x}}+\frac{1}{\varepsilon^{2}} v_{\mathrm{e} f f}\left(\frac{\partial^{2} \mathrm{u}}{\partial \mathrm{x}^{2}}+\frac{\partial^{2} \mathrm{u}}{\partial \mathrm{y}^{2}}\right)- \\
{\left[\frac{v f}{\mathrm{k}}+\frac{\varepsilon \mathrm{C}}{\sqrt{\mathrm{K}}}|\overrightarrow{\mathrm{V}}|\right] \mathrm{u}} \\
\frac{1}{\varepsilon^{2}}\left[u \frac{\partial u}{\partial x}+v \frac{\partial v}{\partial y}\right]=-\frac{1}{\rho f} \frac{\partial p}{\partial y}+\frac{1}{\varepsilon^{2}} v_{e f f}\left(\frac{\partial^{2} v}{\partial x^{2}}+\frac{\partial^{2} v}{\partial y^{2}}\right)- \\
{\left[\frac{v f}{k}+\frac{\varepsilon C}{\sqrt{K}}|\vec{V}|\right] v+\mathrm{g} \beta\left(\mathrm{T}-T_{i}\right)}
\end{gathered}
$$

$|\vec{V}|$ : Dimensionless absolute velocity

$\beta$ : Volumetric thermal expansion coefficient

$v_{\text {eff }}$ : Effective kinematic Viscosity

$K_{\text {eff }}$ Effective thermal conductivity

$\varepsilon$ : Porosity, K: permeability, C: Constant

* Conservation of energy equation:

$$
u \frac{\partial T}{\partial \mathrm{x}}+v \frac{\partial T}{\partial y}=\frac{K_{e f f}}{(\rho C p) f}\left[\left(\frac{\partial^{2} T}{\partial x^{2}}\right)+\left(\frac{\partial^{2} T}{\partial y^{2}}\right)\right]
$$

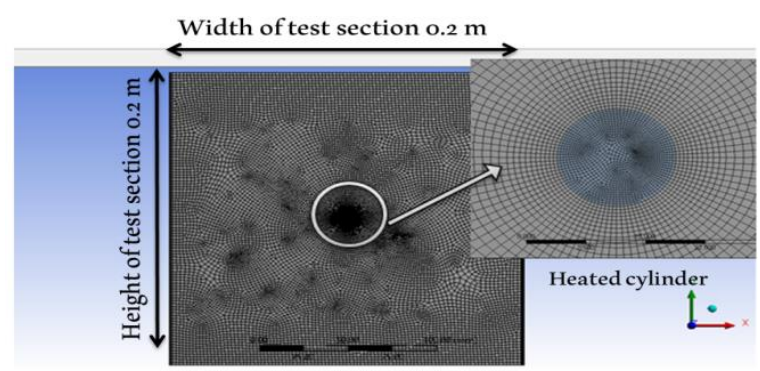

Figure (1): Physical model and mesh generations

\section{Experimental apparatus}

The experimental set-up is shown in Fig. (2) and consists of the following parts:

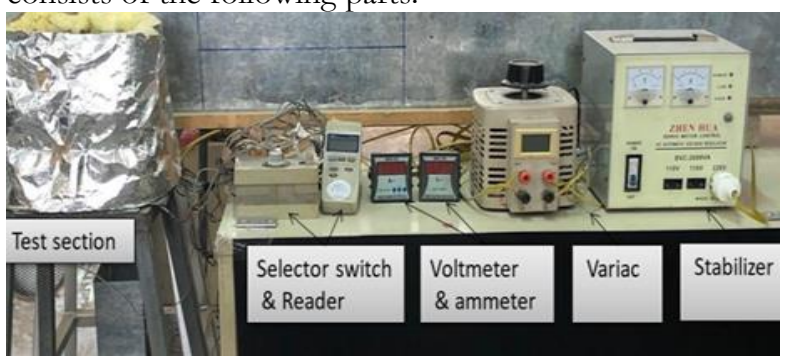

Figure (2): Photographically (the test rig)

\subsection{Test section:}

It is an iron plate of cross-sectional area $0.2 \times 0.2$ $\mathrm{m}^{2}$ and length $0.2 \mathrm{~m}$. The four sides of the duct were isolated by glass wool, while the upper and lower end sides are opened, see fig. 3. A mesh wire (1.5x1.5) $\mathrm{mm}^{2}$ was used to close one end of the test section and to prevent the beads from getting out of the test section and fix it in position. One side of walls of the test section duct is provided by five holes of $1 \mathrm{~cm}$ diameter to fix the heating model element in the test section and connect it to the electrical circuit.

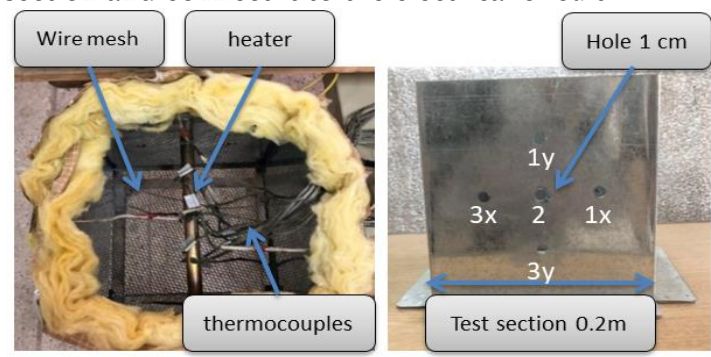

Fig. (3): The test section 


\subsection{Heating element:}

It is consists of two parts, internal part (the heater model) and external part (copper cylinder of $(\mathrm{L}=0.2$ $\left.\mathrm{m}, \mathrm{D}_{\text {out }}=0.01 \mathrm{~m}\right)$ ). The external diameter of the circular cylinder is $0.015 \mathrm{~m}$ and its length is $0.197 \mathrm{~m}$. The temperature distribution is the same in all directions of the heater. To prevent the heat transfer to the side walls of the duct, two pieces of a low conductivity rubber were put to insulate the two heater ends. To measure the heater surface temperature ( $\mathrm{Tw}$ ), twelve thermocouples were fixed on the heater surface in a small hole of $1 \mathrm{~mm}$ diameter, these thermocouples were distributed around the perimeter of the circular heater (3 groups of thermocouples at one face separated by 5 centimeters, each group consist of 4 thermocouples separated $90^{\circ}$ ), see figure (4). To measure the temperature of the inlet and outlet of the test section, six thermocouples were used; three are to measure the inlet air temperature, and other three thermocouples are to measure the outlet temperature.

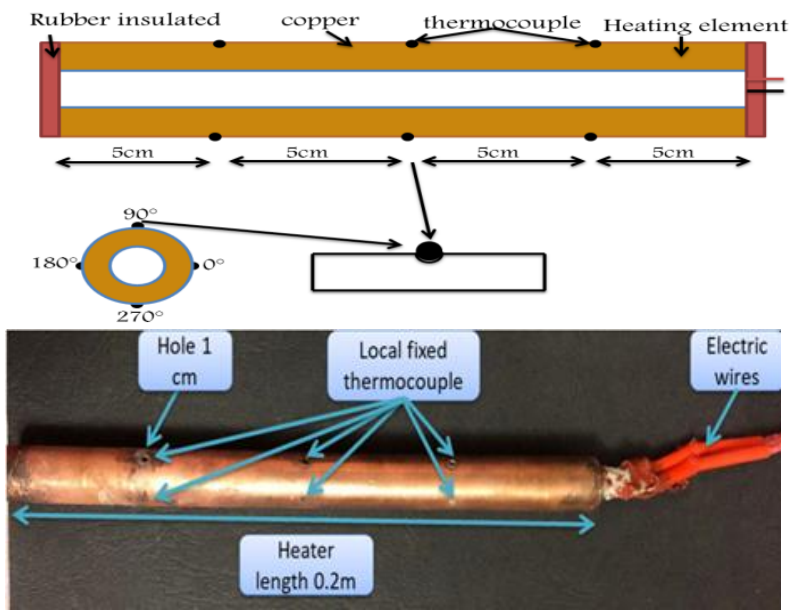

Fig. (4): Distribution of thermocouples around the circular cylinder

\subsection{Electrical devices}

1- Stabilizer: A stabilizer type (DACTRON, STAC JAPAN, St, 2000 W, A.C.V. Voltage Regulator) was joined in parallel to the power supply to assure that incoming mains voltage $(220 \mathrm{~V})$ with an oscillation of $50 \mathrm{~Hz}$ to produce a voltage of $(220 \mathrm{~V})$ with an oscillation of $( \pm 1 \%)$.

2- Variac: A variac type (TDGC) was joined in parallel with the stabilizer to set the heater input voltage as wanted. It receives a voltage range $(110 / 220 \mathrm{~V})$ while it supplies a voltage of $(0-250 \mathrm{~V})$.

3- Voltmeter: Digital Multimeter type (FUKE, DT 9205) was used to measure the voltage that supplied to the heater element. It is able to read a voltage range $(200 \mathrm{~V}-750 \mathrm{~V})$, with an accuracy of $( \pm 0.05 \mathrm{~V})$. 4- Ammeter: Digital Multimeter type (VCTOR, VC 10C) was used to measure the electrical current passing within the heater element. It is able to read a current range (1-100 A) with an accuracy of $( \pm 5 \mathrm{x}$ $\left.10^{-4} \mathrm{~A}\right)$.

\section{Method of calculation}

A. Calculation of the Surface temperature of heater element $\left(\mathrm{T}_{\mathrm{w}}\right)$ by.

$\mathrm{Tw}=\frac{(\mathrm{T} 1+\mathrm{T} 2+\mathrm{T} 3+\mathrm{T} 4+\ldots . .+\mathrm{T} 10+\mathrm{T} 11+\mathrm{T} 12)}{12} \quad \ldots .6$

B. Calculation of mean air temperature $\left(\mathrm{T}_{\text {Mean }}\right)$ by:

$$
\mathrm{T}_{\text {mean }}=\frac{T_{\text {in }}+T_{\text {out }}}{2}
$$

C. Calculation of the membrane temperature over the heater surface by:

$$
\mathrm{T}_{\text {film }}=\frac{T_{\text {mean }}+T_{w}}{2}
$$

D. Total power supply to the heater element:

$$
\mathrm{Q} \mathrm{t}=\mathrm{V} * \mathrm{I} * \operatorname{COS}(\theta)
$$

E. Heat losses:

$$
Q_{\text {loss }}=Q_{t}-Q_{\text {air }}
$$

F. Net heat transfer to air

$$
\mathrm{q}=\mathrm{Q}_{\mathrm{t}}-\mathrm{Q}_{\mathrm{loss}}
$$

G. Calculation of the average heat transfer coefficient

(h) by ${ }^{[17]:-}$

$$
\mathrm{h}=\frac{\mathrm{Qt}}{\mathrm{As}(\mathrm{Tw}-\mathrm{Tmean})}
$$

H. Effective thermal conductivity $(\mathrm{km})$ :-

$$
k_{m}=\varepsilon k_{f}+(1-\varepsilon) k_{s} \quad \ldots .13
$$

I. Calculations of the average Nusselt Number by:

$$
N u=\frac{h \mathrm{D}_{h}}{k_{\text {air }}}
$$

J. Calculation of the grashof Number by:

$$
G r=\frac{g \beta \Delta T d^{3}}{v^{2}}, \quad \beta=\frac{1}{T_{\text {film }}}
$$

K. Calculation of the Raleigh Number by:

$$
\mathrm{R} a=G_{r} . P_{r}
$$

L. Calculation of the Surface temperature face of the heater by:

$$
T_{w \theta}=\frac{\Sigma \mathrm{T}_{w}}{3}
$$

M. Calculation of the local Heat Transfer Coefficient by:

$$
\mathrm{h}_{\theta}=\frac{\mathrm{q}}{A_{s}\left(\mathrm{~T}_{\mathrm{w} \theta}-\mathrm{T}_{\text {mean }}\right)}
$$

N. Calculation of the local Nusselt Number by:

$$
N u_{\theta}=\frac{h_{\theta} D_{h}}{k_{m}}
$$

\section{Properties of porous media}

Porosity $(\varepsilon)$ is the volume of the fluid that fills the medium to the total volume of the porous media and can be defined as the pores between the parts of solid material containing the fluid passing through it. The porosity can be expressed mathematically as:-

$$
\varepsilon=\frac{\forall^{\circ}}{\forall} \quad \ldots .20
$$

Where, $\forall^{\circ}$ is the difference between the total volume $(\forall)$ and the volume of solid material $(\forall \mathrm{s})$.

$$
\forall^{\circ}=\forall-\forall \mathrm{s}
$$

First weighting the sample then found its volume $(\forall \mathrm{s})$ by dividing the mass of sample $\left(\mathrm{m}_{\mathrm{s}}\right)$ to the average density $\left(\rho_{\mathrm{s}}\right)$ as:

$$
\forall_{s}=\frac{m_{s}}{\rho_{s}}
$$

The sample of glass beads was added to the graduated cylinder, and the volume $(\forall)$ of the sample was obtained by measuring the graduated cylinder. This checking was repeated several times. The porosity of the glass beads $(5 \mathrm{~mm})$ was found empirically to be $(0.41)$. 


\section{Results and Discussion}

\subsection{Effect of changing heat flux on the} temperature distribution:

Effect of changing the heat flux [(30 V (40764 $\left.\left.\mathrm{W} / \mathrm{m}^{2}\right)\right)$, (35 V $\left.\left(55485 \mathrm{~W} / \mathrm{m}^{2}\right)\right)$, (40 V $\left.\left(72470 \mathrm{~W} / \mathrm{m}^{2}\right)\right)$, and $\left.\left(45 \mathrm{~V}\left(94268 \mathrm{~W} / \mathrm{m}^{2}\right)\right)\right]$ is on the temperature distribution. For any heater location, the local surface temperature increases as the heat flux increases. The temperature distribution on the perimeter of the heater is almost constant, as shown in fig. (5). When changing the cylinder locations to the bottom of the test section, the behavior of the temperature distribution is similar, but the values become less because the hot air rises to the top and the cold air descends down. The temperature distribution around the angles has been studied because it is variable around the circumference of the cylinder in case of absence of porous media, but it is constant in case of presence of porous media.

Figure (6) shows that the local Nusselt number gradually decreases with the increase in the angle until $\left(90^{\circ}\right)$ and then increases with the increased angle until $\left(270^{\circ}\right)$. This is due to the effect of the buoyancy force and thickness of the boundary layer. The hot air at $(\Theta$ $=90^{\circ}$ ) decreases the local heat transfer coefficient, so the local Nusselt number will decrease according to ( $\mathrm{h}=$ eq. (18), $\mathrm{Nu}=$ eq. (19). In addition, the local Nusselt number in eqs. $(18,19)$ increased as the heat flux is increased. The increasing in $\Delta \mathrm{T}$ is less than increasing in $\mathrm{Q}$, so the heat transfer coefficient will increase, also the local Nusselt number increases.

The temperatures distribution pattern around the cylinder perimeter by using ANSYS is presented in fig (7). At constant heater location (p2), $5 \mathrm{~mm}$ diameter, the effect of changing the heat flux on the temperatures values are presented in table (1). The temperature distribution patterns around the perimeter of the cylinder when changing the values of the heat flux are similar to fig. (7), while the temperature values are increasing as the value of the heat flux increases, see table (1). Figure (8) shows a comparison between experimental and theoretical values.

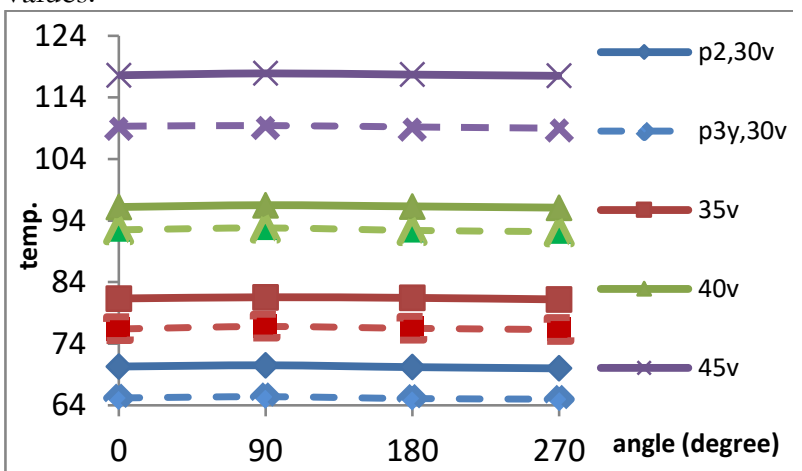

Figure (5): Average temperature $\left({ }^{\circ} \mathrm{C}\right)$ with angle for change voltage $(30,35,40,45 \mathrm{v}),(\mathrm{p} 2,3)$ in y-axis, 5 $\mathrm{mm}$

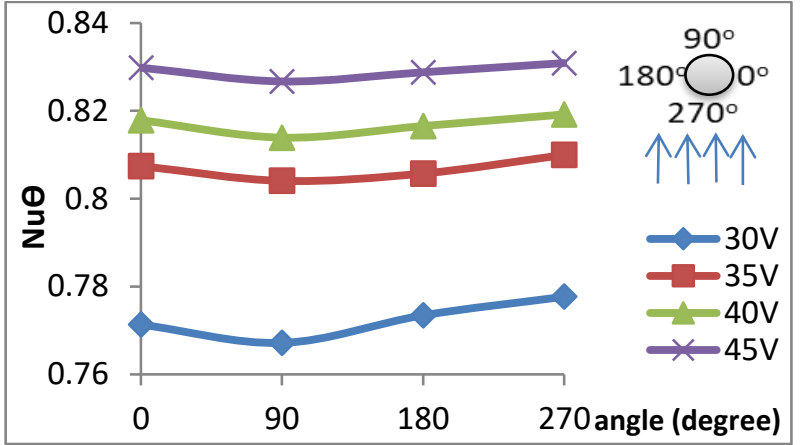

Figure (6): Local Nusselt number with Angle for change voltage $(30,35,40,45 \mathrm{v})$ in $\mathrm{Y}$-axis, $5 \mathrm{~mm}$, p2

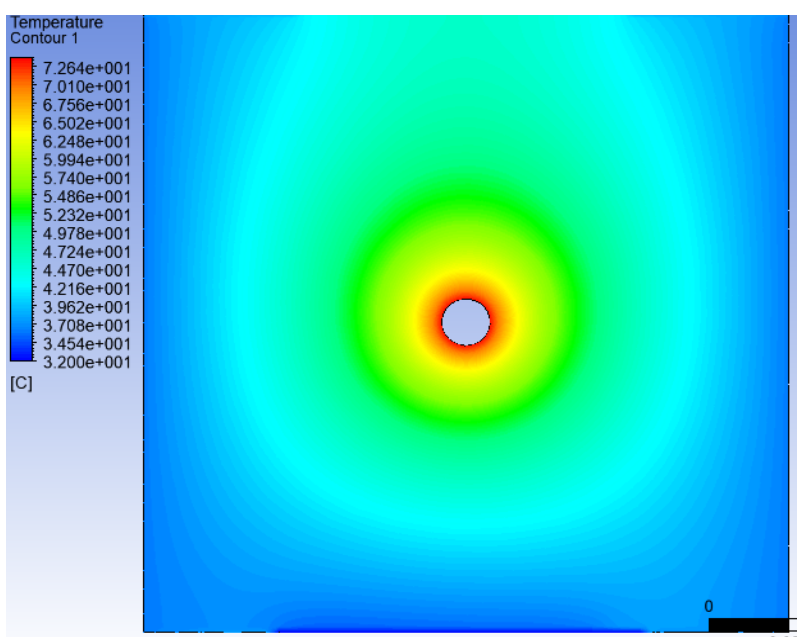

Figure (7): Temperature distribution on the cylinder perimeter $(\mathrm{p} 2,30 \mathrm{v}$, and $5 \mathrm{~mm})$

Table (1): Effect of changing the heat flux and a comparison of the theoretical solution with the experimental work with $5 \mathrm{~mm}$ diameter

\begin{tabular}{|c|c|c|c|c|}
\hline $\begin{array}{c}\mathbf{Q} \\
\left(\mathbf{W} / \mathbf{m}^{2}\right)\end{array}$ & $\begin{array}{c}40764 \\
\left(\mathbf{W} / \mathbf{m}^{2}\right)\end{array}$ & $\begin{array}{c}55485 \\
\left(\mathbf{W} / \mathbf{m}^{2}\right)\end{array}$ & $\begin{array}{c}\mathbf{7 2 4 7 0} \\
\left(\mathbf{W} / \mathbf{m}^{2}\right)\end{array}$ & $\begin{array}{c}\mathbf{9 4 2 6 8} \\
\left(\mathbf{W} / \mathbf{m}^{2}\right)\end{array}$ \\
\hline $\begin{array}{c}\mathbf{T h e o .} \\
\mathbf{T}_{\text {avg }}\end{array}$ & $72{ }^{\circ} \mathrm{C}$ & $86.08^{\circ} \mathrm{C}$ & $101.5^{\circ} \mathrm{C}$ & $121.4{ }^{\circ} \mathrm{C}$ \\
\hline $\begin{array}{c}\mathbf{E x p} . \\
\mathbf{T}_{\text {avg }}\end{array}$ & $70.25^{\circ} \mathrm{C}$ & $81.38^{\circ} \mathrm{C}$ & $96.27^{\circ} \mathrm{C}$ & $117.67^{\circ} \mathrm{C}$ \\
\hline$\frac{\boldsymbol{T}_{\text {theo }}-\boldsymbol{T}_{\text {exp }}}{\boldsymbol{T}_{\text {theo }}}$ & $2.43 \%$ & $5.46^{\circ} \%$ & $5.15 \%$ & $3.072 \%$ \\
\hline
\end{tabular}

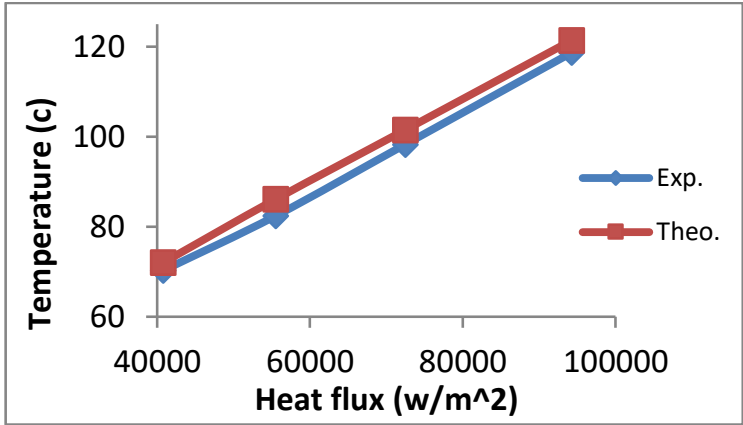

Figure (8): Comparison between experimental and theoretical values

\subsection{Effect of changing the heater positions within the test section.}

In fig. (9) When heater positions within the test section by $5 \mathrm{~cm}$ distance between one location and 
another, see fig. (3), it is note that when changing the cylinder locations, the behavior of the temperature distribution is similar, but the values are different, where when moving the cylinder from the top down to the bottom, temperatures decrease as shown in figures (9), because the hot air rises to the top and the cold air descends down (maximum value of difference temperature ratio between the top and bottom ((Tmax -Tmin) / Tmax) at $30 \mathrm{v}$ is $7.22 \%$ ) and when moving left and right, the temperature is similar in behavior and values.

At constant heat flux $30 \mathrm{v}\left(40764 \mathrm{~W} / \mathrm{m}^{2}\right)$ and 5 $\mathrm{mm}$ diameter the effect of changing the location of the cylinder inside the test section on the temperatures values and direction of flow (vortices) by ANSYS is presented in the figures (10) A and (10) B. As shown in the figure (10: A), the temperature distribution patterns around the perimeter of the cylinder when changing the location are similar, but the values decrease as getting the cylinder down within the test section. And, this is comparable to what has been achieved in the experimental tests. As for the distribution of the flow lines (air movement within the test section) as shown, the maximum speed is after the cylinder and on both sides of the test section, as well as the two vortices (eyes) emerging from free convection caused by different densities are symmetrical on both sides of the cylinder and change its position as it withdraws to the top with the change site of the cylinder to the top. While in the figure (10: B) it is noticed that the flow around the cylinder is asymmetric, and the two emerging vortices (eyes) are not symmetrical on either side of the cylinder (at the side positions) because of the differences in the speed of air movement, where the highest value is away from the location of the cylinder near the wall to the down, and the flow direction after the cylinder is going to up.

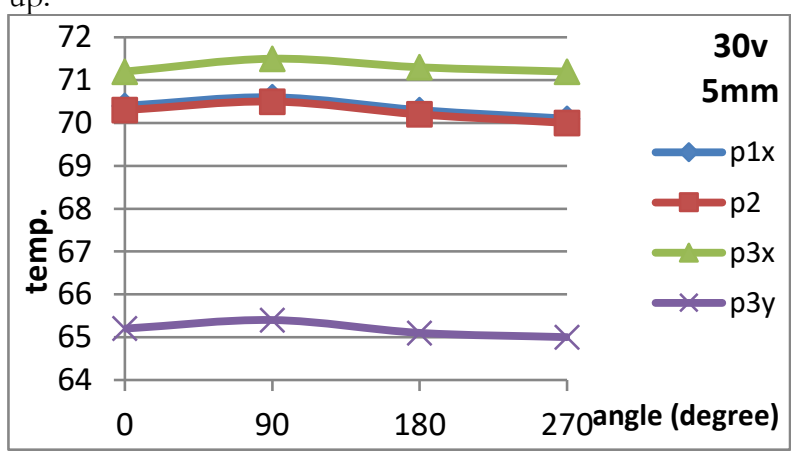

Figure (9): Average temperature $\left({ }^{\circ} \mathrm{C}\right)$ with Angle for change Position in $\mathrm{x} \& \mathrm{y}$ axis, $5 \mathrm{~mm}$ diameter.

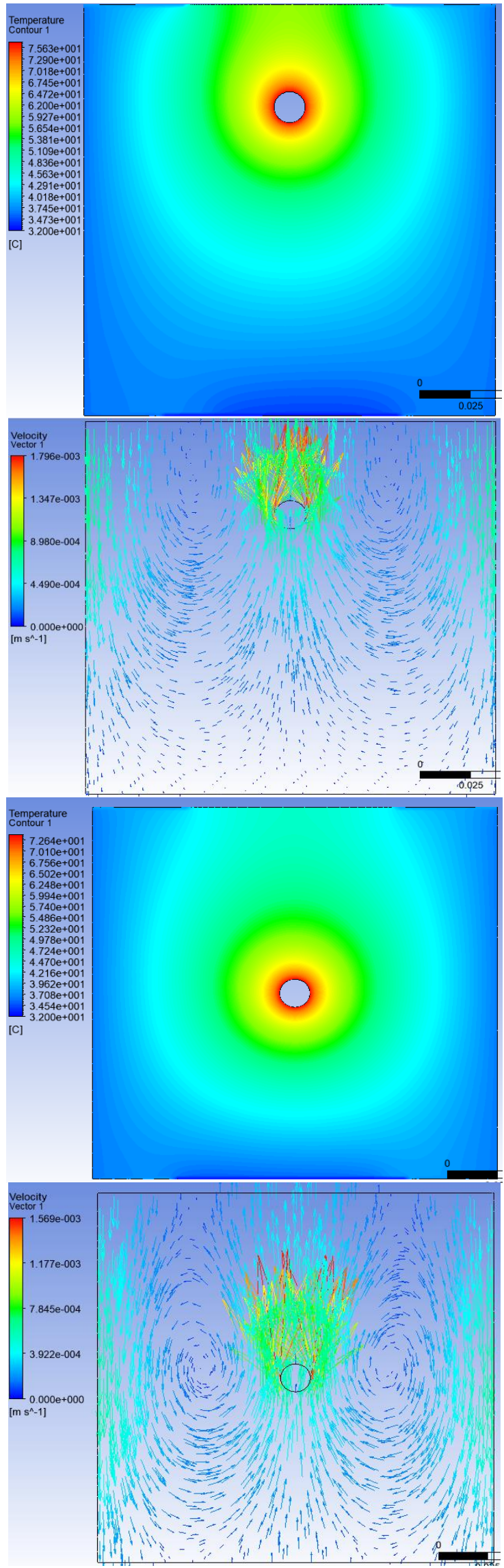




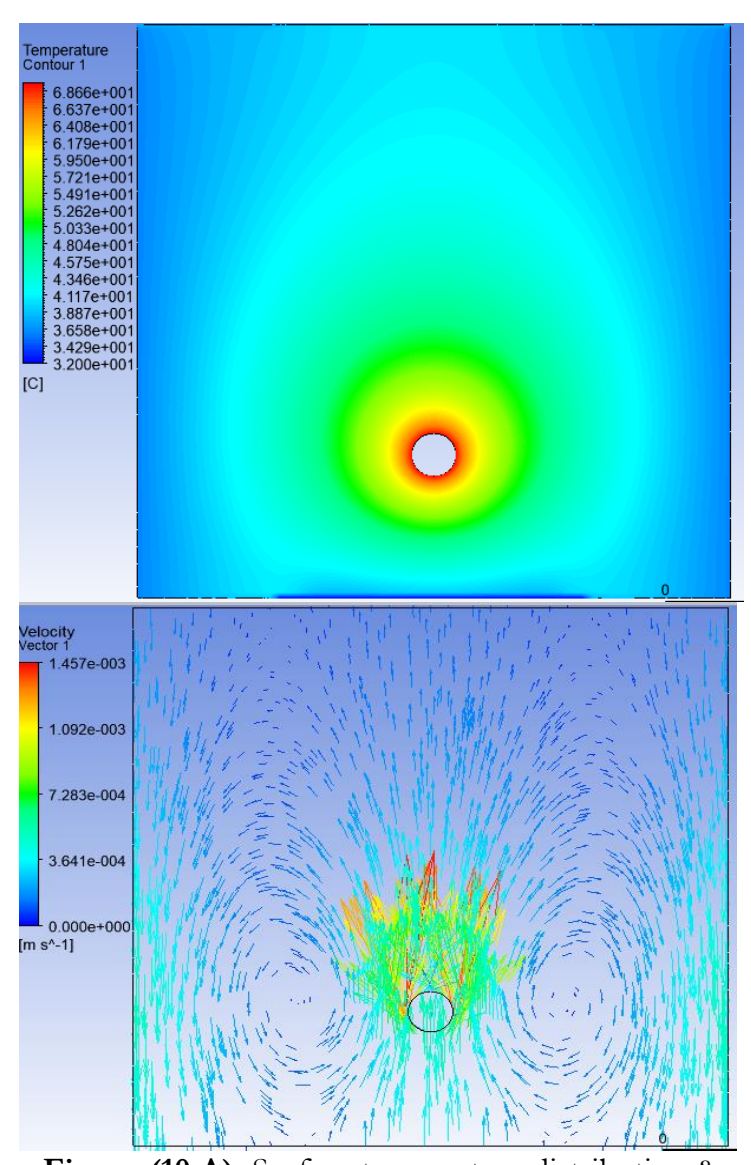

Figure (10 A): Surface temperature distribution \& the direction of vortices at different location in $y$-axis

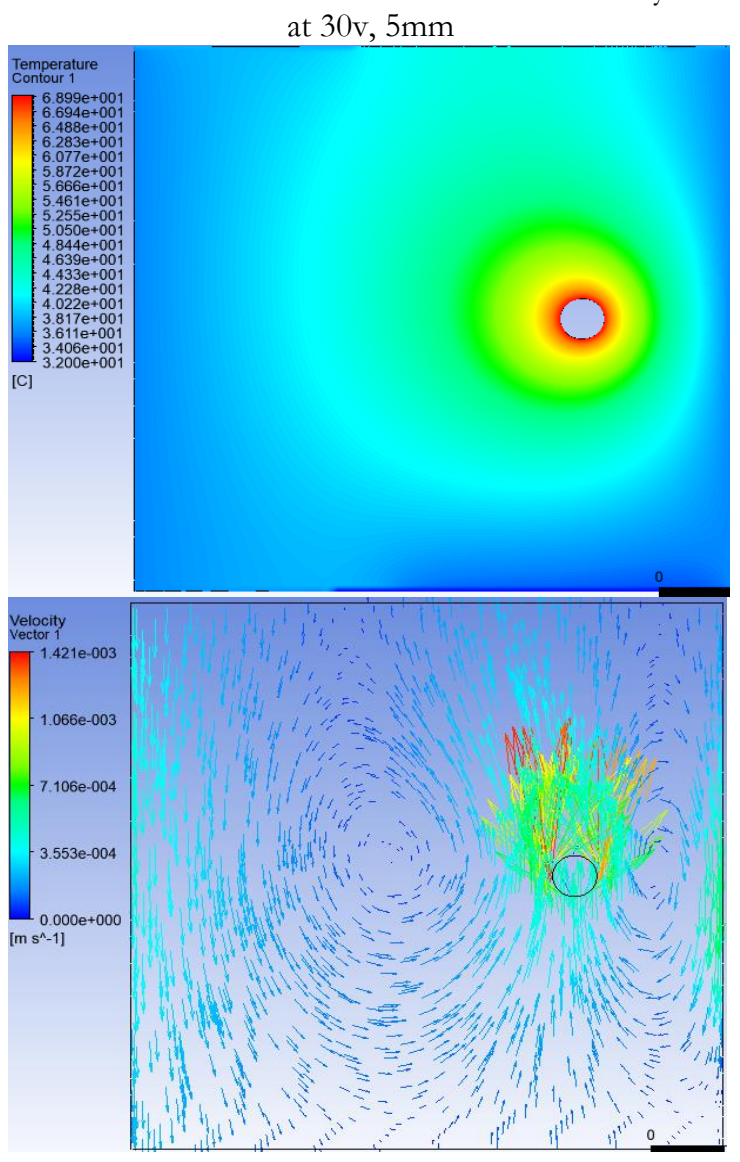

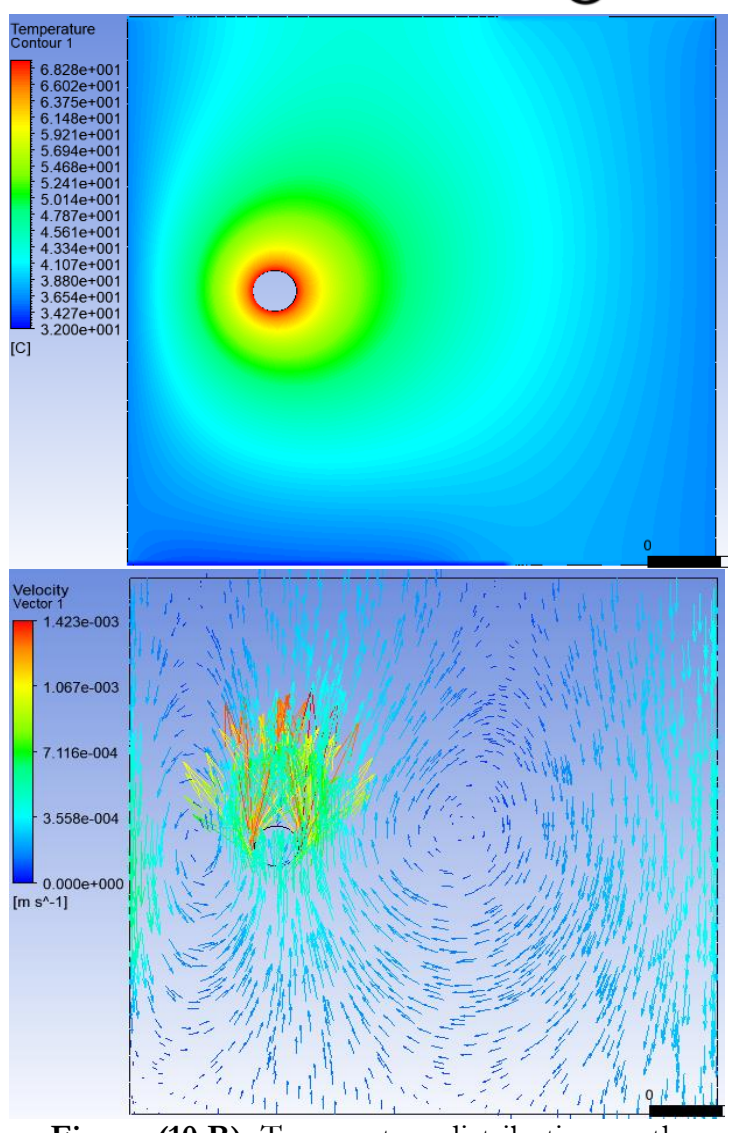

Figure (10 B): Temperature distribution on the cylinder perimeter and the direction of vortices at different location in X-axis at $30 \mathrm{v}, 5 \mathrm{~mm}$.

\subsection{Average Nusselt number with Raleigh number}

For constant location and beads diameter $(5 \mathrm{~mm})$ and different values of heat flux $[(30 \mathrm{~V}$ $\left.\left(40764 \mathrm{~W} / \mathrm{m}^{2}\right)\right),\left(35 \mathrm{~V}\left(55485 \mathrm{~W} / \mathrm{m}^{2}\right)\right)$, (40 V $(72470$ $\left.\mathrm{W} / \mathrm{m}^{2}\right)$ ), and $\left.\left(45 \mathrm{~V}\left(94268 \mathrm{~W} / \mathrm{m}^{2}\right)\right)\right]$, fig. (11) shows that the average Nusselt number increases as the Raleigh number increase. Where, when increasing the heat flux, $\Delta T$ increases also, so Raleigh number will increase (eqs. 15 and 16), and Nusselt number increases with increase heat flux, see fig (6). In addition, Nusselt increases when moving the cylinder to the bottom within the test section.

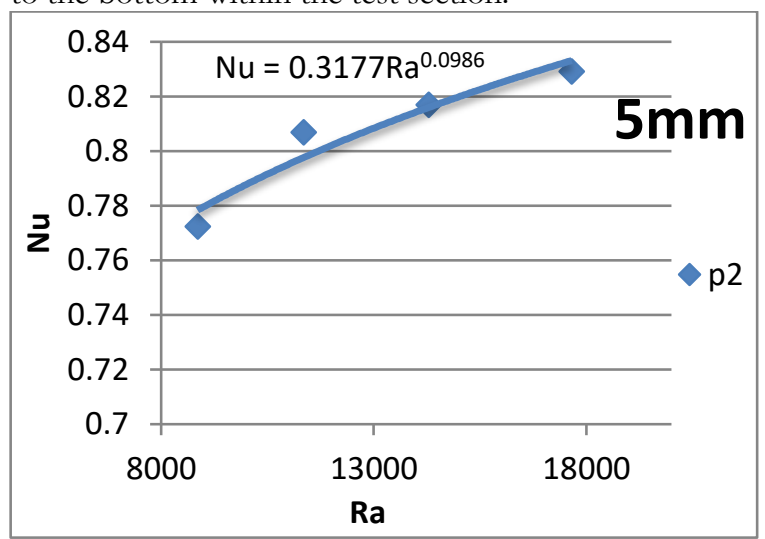

Figure (11): Average Nusselt number with Raleigh number, $5 \mathrm{~mm}$ diameter 


\subsection{Heat transfer enhancement}

Table (2) explains the effectiveness of using the porous media in the improvement of the convection heat transfer of the heater element in the cross airflow. The average heat transfer coefficient of the heater element inside the porous media is larger more than that in clear duct at the same rate of the airflow (mass flow). The improvement in heat transfer for the heater embedded in porous media is $48.6 \%$ percentage $[\mathrm{E} \%=(\mathrm{h}$ porous $-\mathrm{h}$ empty $) / \mathrm{h}$ porous $]$. Figure (12) shows the two cases of temperature distribution, with and without porous media, where the maximum temperature in case of absence the porous media is $113.1{ }^{\circ} \mathrm{C}$, while in case of presence porous media, it is $72.64{ }^{\circ} \mathrm{C}$ at the same voltage $70 \mathrm{~V}$

Table (2): Heat transfer enhance ( 2 2, $\mathrm{d}_{\mathrm{s}}=5 \mathrm{~mm}, 30$

\begin{tabular}{|c|c|c|c|}
\hline $\begin{array}{c}\text { Test } \\
\text { section }\end{array}$ & Tw $\left({ }^{\circ} \mathbf{C}\right)$ & $\begin{array}{c}\mathbf{h} \\
\left(\mathbf{W} / \mathbf{m}^{2} \cdot \mathbf{C}\right)\end{array}$ & percentage \\
\hline porous & 72.64 & 21.11 & \multirow{2}{*}{$48.6 \%$} \\
\hline empty & 113.1 & 10.85 & \multirow{2}{*}{ emp } \\
\hline
\end{tabular}

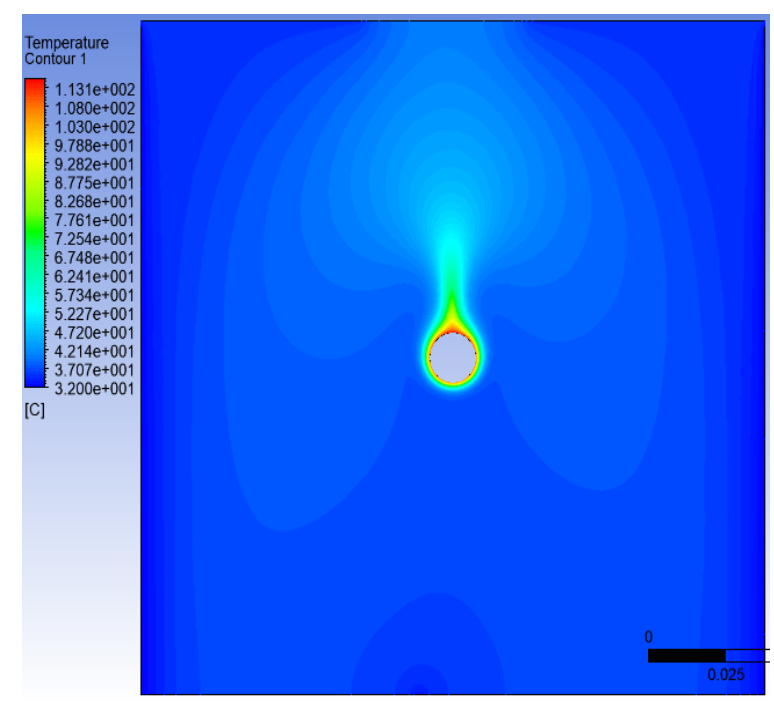

Figure (12 A): Temperature distribution in case of without porous media Max. Temperature is $113.1{ }^{\circ} \mathrm{C}$

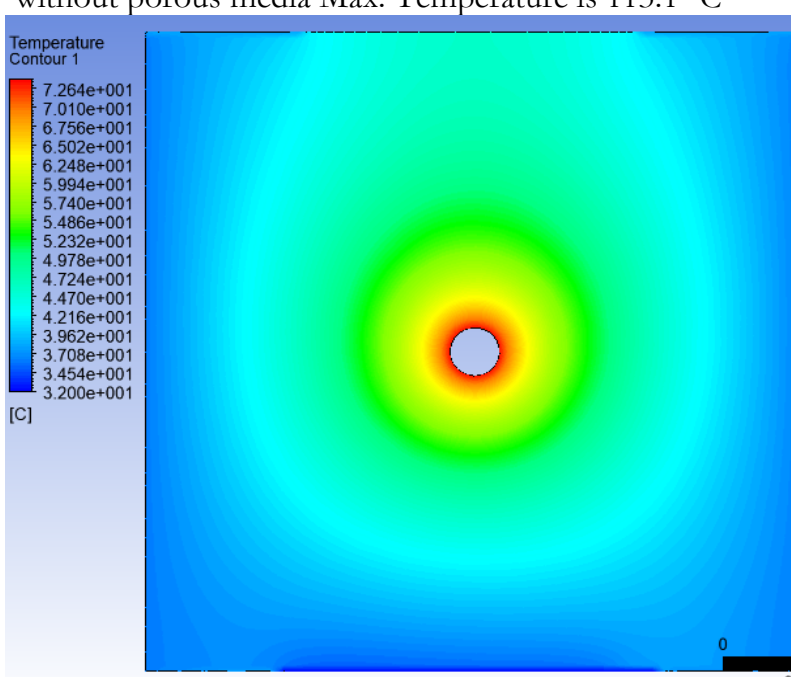

Figure (12 B): temperature distribution in case of with porous media Max. Temperature is $72.64{ }^{\circ} \mathrm{C}$
7.5 Comparisons of nusselt number and Raleigh number with previous work

Figure (11) shows that the average Nusselt number has a similar behavior to those presented in Ref. [7], fig (13). In both researches, the average Nusselt number increased as the Raleigh number was increased. Table (3) shows the correlation equations for $\mathrm{Nu} \& \mathrm{Ra}$.

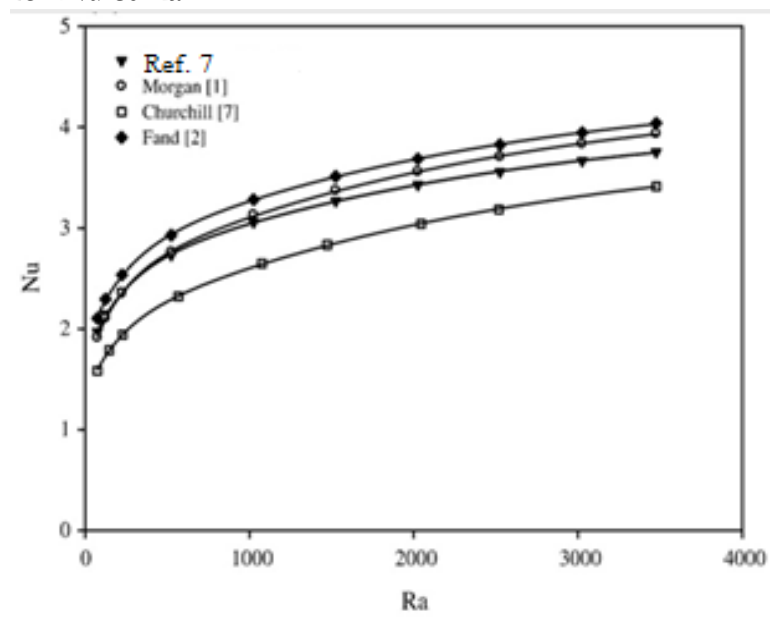

Figure (13): Average Nusselt numbers with Raleigh number (Ref. 7)

Table (3): Correlation equations for $\mathrm{Nu} \& \mathrm{Ra}$

\begin{tabular}{|c|c|c|}
\hline Equation & range of $\mathbf{R a}$ & position \\
\hline $\mathbf{N u}=\mathbf{0 . 3 1 7 7} \mathbf{R a} \mathbf{0}^{\mathbf{0 . 0 9 8 6}}$ & $7000<\mathrm{Ra}<17000$ & $\begin{array}{c}\text { (present } \\
\text { work) p2 }\end{array}$ \\
\hline $\mathbf{N u}=\mathbf{0 . 9 5 4} \mathbf{R a}^{\mathbf{0 . 1 6 8}}$ & $74<\mathrm{Ra}<3400$ & ref. 7 \\
\hline
\end{tabular}

\section{Conclusions:}

The present research focuses on the effect of using the porous media on free convection heat transfer from a cylinder placed in a different location within the test. The conclusions based on the experimental and theoretical results are as follows:

1. The maximum temperature is at $\theta=90^{\circ}$, and the minimum temperature is at $\theta=270^{\circ}$, where the buoyancy force effect appeared.

2. The local Nusselt number decreases at $\theta=90^{\circ}$ and then increases until $270^{\circ}$.

3. The Nusselt number at a constant heat flux and beads diameter $(5 \mathrm{~mm})$ is directly proportional to the Rayleigh number $\mathrm{Nu}=0.3177 \mathrm{Ra}^{0} \cdot 0986$. It also increases with the increase in heat flux at constant Rayleigh numbers.

4. The surface temperature values change when moving up and down, where the effect of buoyancy appears (the maximum difference between the top and the bottom is $7.22 \%$ ).

5 . The use of porous material significantly improved the heat transfer by $(48.6 \%)$.

6. The maximum percentage change between the experimental and theoretical results is $5.46 \%$.

7. A comparison was performed between the present research with the previous (studies and it was given a similar pattern and good agreement.

8. By ANSYS, the maximum velocity in case of without beads is at the duct wall and after cylinder 
$\left(1.71 \times 10^{-1} \mathrm{~m} / \mathrm{s}\right)$, and in case of with beads, it is after the cylinder only $\left(1.79 \times 10^{-3} \mathrm{~m} / \mathrm{s}\right)$.

\section{References}

[1] Kaviany, M, 1998, "Principles of Heat Transfer in Porous Media" Chap.1-2, Second edition, the university of Michigan.

[2] Bejan, A., 2003, "Convection Heat Transfer", Chap. 10, John Wiley and Sons Ins., 1984.

[3] Omar Rafae Alomar" Numerical Study of Inertia Effect on Natural Convection in A Horizontal Porous Cavity", M.Sc. Thesis, Mosul Univ, Iraq.

[4] Nawaf H. Saeid," Analysis of free convection about a horizontal cylinder in a porous media using a thermal non-equilibrium model" International Communications in Heat and Mass Transfer 33 (2006) 158-165.

[5] M. Ashjaee," Experimental Study of Free Convection Heat Transfer from Horizontal Isothermal Cylinders Arranged in Vertical and Inclined Arrays", Heat Transfer Engineering, 28(5):460-471, 2007.

[6] Yorwearth L. Jamin," Natural Convection Heat Transfer Enhancements from a Cylinder Using Porous Carbon Foam: Experimental Study", Journal of Heat Transfer, 2008, Vol. 130 / 122502-1.

[7] Ş. Özgür Atayılmaz, "Experimental and numerical study of the natural convection from a heated horizontal cylinder", International Communications in Heat and Mass Transfer 36 (2009) 731-738

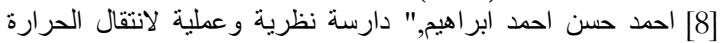

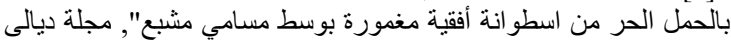

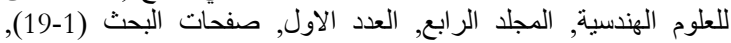

حزيران 2011

[9] P. Nagaraju, "Studies on heat and mass transfer problems in saturated porous media", university grants commission, MRP(s)-165/08-09, 3/4/2009.

[10] E. Shakeri, "Free Convection Heat Transfer over a Vertical Cylinder in a Saturated Porous Medium Using a Local Thermal Non-equilibrium Model", p.p 93:453-460, 24 February 2012.

[11] Stig Grafsrønningen, "Natural convection heat transfer from three vertically arranged horizontal cylinders with dissimilar separation distance at moderately high Rayleigh numbers", International Journal of Heat and Mass Transfer 57 (2013) 519_ 527.

[12] Anna A.Bocharova and Irina V. Plaksina," Convection Heat Transfer on a Vertical Surface in Porous Media”, Vol. 685, pp 272-275, 2016.
[13] Sandra Corasaniti and Fabio Gori," Natural convection around a vertical cylinder (thermal probe) immersed in a porous medium", International Communications in Heat and Mass Transfer, 81 (2017) 72-78.

[14] Hosny Abou-Ziyan,” Experimental Investigation of Free Convection from Short Horizontal Cylinder to Newtonian and Power-Law Liquids of Large Prandtl Numbers", Experimental Thermal and Fluid Science (2017).

[15] Ahmed H. Ahmed, " Forced Convection about a Horizontal Cylinder Embedded in a Porous Medium" Foundation of Technical Education- Technical Institute Hawija Journal of Kirkuk University Scientific Studies, Iraq, Vol.5, No.2, 2010.

[16] Zaid Salman Ubaid, 2019, "numerical and experimental study of using different cooling method for photovoltaic panel", M.Sc. University of Technology Iraq.

[17] Qahtan, A. Flaiyh, 2005" Forced Convection Heat Transfer Through and over porous layer on a heated wall at constant temperature", M.Sc. University of Technology Iraq.

\section{Calculation of uncertainty}

The Uncertainty of Raleigh number is calculated from:

$$
\mathrm{Ra}=\frac{\mathrm{g} \beta \Delta_{T} \mathrm{~d}^{3}}{v \alpha}
$$

The values of variables that measured and their uncertainties are given below in this table:

\begin{tabular}{|c|c|c|c|c|}
\hline No. & Variable & Value & Uncertainties & Units \\
\hline 1. & $\beta$ & $2.921 \times 10^{-3}$ & $\pm 5.208 \times 10^{-6}$ & $1 / \mathrm{k}$ \\
\hline 2. & $\Delta_{T}$ & 71.48 & \pm 1.011 & $\mathrm{k}$ \\
\hline 3. & $\mathrm{~d}$ & 15 & \pm 0.5 & $\mathrm{~mm}$ \\
\hline 4. & $v$ & $1.987 \times 10^{-5}$ & $\pm 7.6 \times 10^{-8}$ & $\mathrm{~m}^{2} / \mathrm{s}$ \\
\hline 5. & $\alpha$ & $2.768 \times 10^{-5}$ & $\pm 1.140 \times 10^{-7}$ & $\mathrm{~m}^{2} / \mathrm{s}$ \\
\hline
\end{tabular}

$$
\begin{gathered}
\frac{\omega R a}{R a}=\left[\left(\frac{\alpha_{\beta} \omega_{\beta}}{\beta}\right)^{2}+\left(\frac{\alpha_{\Delta_{T} \omega_{\Delta_{T}}}}{\Delta_{T}}\right)^{2}+\left(\frac{\alpha_{d} \omega_{d}}{d}\right)^{2}+\left(\frac{\alpha_{v} \omega_{v}}{v}\right)^{2}+\right. \\
\left.\left(\frac{\alpha_{\alpha} \omega_{\alpha}}{\alpha}\right)^{2}\right]^{0.5} \\
\frac{\omega R a}{R a}=\left[\left(\frac{1 \times 2.921 \times 10^{-3}}{5.208 \times 10^{-6}}\right)^{2}+\left(\frac{1 \times 1.011}{71.48}\right)^{2}+\left(\frac{3 \times 0.5}{15}\right)^{2}+\right. \\
\left.\left(-\frac{1 \times 7.6 \times 10^{-8}}{1.987 \times 10^{-5}}\right)^{2}+\left(-\frac{1 \times 1.140 \times 10^{-7}}{2.768 \times 10^{-5}}\right)^{2}\right]^{0.5}=0.1011
\end{gathered}
$$

